\title{
ALTERAÇÕES NA QUALIDADE DO CAFÉ SUBMETIDO A DIFERENTES FORMAS DE PROCESSAMENTO E SECAGEM
}

Marcelo Ribeiro Malta ${ }^{1}$, Sttela Dellyzete Veiga Franco da Rosa², Priscilla Magalhães de Lima ${ }^{3}$, Larissa de Oliveira

Fassio $^{4}$, Juliano Batista dos Santos ${ }^{5}$

\begin{abstract}
RESUMO
Pesquisas recentes têm indicado várias alterações nos grãos de café decorrentes do processamento e secagem. Assim, neste trabalho objetivou-se verificar a influência da secagem lenta e secagem rápida sobre alguns parâmetros bioquímicos e fisiológicos de grãos de café e sobre a qualidade da bebida. Cafés da cultivar Catuaí Vermelho IAC 144 foram colhidos e submetidos a três formas de processamento, café natural, desmucilado e despolpado, e dois métodos de secagem, lenta à sombra em telados suspensos e secagem rápida em secadores de camada fixa a $35^{\circ} \mathrm{C}$. Após secagem, os cafés foram submetidos às seguintes avaliações: análise sensorial, condutividade elétrica, lixiviação de potássio, atividade enzimática da polifenoloxidase, acidez total titulável e análises fisiológicas. Há interação entre métodos de processamento e de secagem sobre a qualidade sensorial do café, sendo mais evidentes os efeitos da secagem. Os cafés obtidos por via úmida tem maior tolerância à secagem do que os processados por via seca. Melhor qualidade sensorial é obtida nos cafés submetidos à secagem lenta, independentemente da forma de processamento utilizada. Cafés de melhor qualidade sensorial apresentam melhor qualidade fisiológica.
\end{abstract}

Palavras-chave: análise sensorial, Coffea arabica L, pós-colheita

\section{ABSTRACT \\ CHANGES IN QUALITY OF COFFEE SUBMITTED TO DIFFERENT FORMS OF PROCESSING AND DRYING}

Recent research has indicated various changes in coffee grains resulting from processing and drying. Therefore, the purpose of this study was to verify the effect of slow drying and rapid drying on some biochemical and physiological parameters of coffee grains and on quality of the beverage. Coffee beans of the cultivar Catuaí Vermelho IAC 144 were collected and subjected to three forms of processing, natural, demucilaged and pulped coffees, as well as two methods of drying: slowly in the shade on suspended screens and rapid drying in fixed bed dryers at $35{ }^{\circ} \mathrm{C}$. After drying, the coffee grains were submitted to the following evaluations: sensory analysis, electrical conductivity, potassium leaching, polyphenol oxidase enzyme activity, total titratable acidity and physiological analyses. There is interaction between processing and drying methods on the sensory quality of the coffee, where the effects of drying are more evident. Coffees obtained by wet processing have greater tolerance to drying than those obtained by dry processing. Better sensory quality is obtained in coffees submitted to slow drying, regardless of the processing method used. Coffees with better sensory quality show better physiological quality.

Keywords: sensory analysis, Coffea arabica L., post-harvest

Recebido para publicação em 27/05/2013. Aprovado em 23/07/2013.

1 - Eng. Agrônomo. Pesquisador EPAMIG - Lavras,MG - 37200-000. marcelomalta@epamig.ufla.br

2 - Eng. Agrícola. Pesquisadora EMBRAPA - sttela.rosa@embrapa.br

3 - Eng. de Alimentos. priscillamagalhaes.lima@gmail.com

4 - Tecnóloga em Alimentos. Mestranda em Engenharia de Alimentos da UFLA. larissafassio@yahoo.com.br

5 - Biólogo, EPAMIG. Julianobatista@epamig.ufla.br 


\section{INTRODUÇÃO}

Após a colheita, o café pode ser processado de duas formas, por via seca e via úmida. No processamento por via seca, o fruto é secado na sua forma integral (com casca), dando origem aos cafés denominados em coco ou naturais. $\mathrm{O}$ processamento por via úmida consiste na retirada da casca, polpa e/ou mucilagem do fruto maduro, que são substratos propícios ao desenvolvimento de microrganismos que podem provocar a ocorrência de fermentações prejudiciais à qualidade final do produto (MALTA, 2011; MALTA et al., 2008).

A forma de processamento por via úmida origina os cafés descascados, despolpados ou desmucilados. Para a obtenção do café cereja descascado, os frutos são descascados mecanicamente e parte da mucilagem ainda permanece aderida ao pergaminho dos frutos. Na obtenção do café despolpado, após o descascamento, a parte da mucilagem que ainda estava aderida aos frutos é removida em tanques de fermentação biológica. Se a remoção desta mucilagem remanescente for realizada mecanicamente, tem-se, então, o café desmucilado (MALTA, 2011).

Vários estudos sinalizam que a composição química dos grãos de café são dependentes da forma de processamento utilizada (BYTOF et al., 2005; KNOPP et al., 2006), contribuindo para características distintas na qualidade. Em pesquisas recentes tem-se verificado variações no conteúdo de glicose e frutose, bem como de aminoácidos livres nos grãos crus de café, dependendo da forma de processamento, sem, no entanto, descreverem as interferências das condições de secagem (BYTOF et al., 2005; BYTOF et al., 2000).

Durante o processamento e secagem, alterações fisiológicas podem ocorrer comprometendo a qualidade da bebida do café. Vários estudos têm sido realizados no sentido de correlacionar a manutenção da qualidade fisiológica com a qualidade sensorial da bebida durante esse processo (BORÉM et al., 2008; OLIVEIRA, 2010; Saath et al., 2010; TAVEIRA, 2009). Grãos com sistemas de membranas celulares mal estruturados, desorganizados e danificados, devido a danos por temperaturas elevadas, permitem maior lixiviação de solutos, apresentando maiores valores de condutividade elétrica (MALTA et al., 2005; PRETE, 1992).

A taxa de secagem tem efeito na qualidade do grão. Altas taxas podem provocar danos físicos, descoloração do produto, manchas, entre outros (AFONSO JÚNIOR, 2001; RIBEIRO et al., 2003). A velocidade de secagem do café é influenciada por vários fatores como temperatura e fluxo de ar de secagem, umidade e temperatura do ar ambiente, teor de água inicial e final do produto (AFONSO JÚNIOR et al. 2004a; CORRÊA et al., 2002; RIBEIRO et al., 2003).

Diante do exposto, objetivou-se neste trabalho verificar a influência da secagem lenta e secagem rápida sobre algumas variáveis bioquímicas, fisiológicas e da qualidade de bebida de grãos de café processados por via úmida e via seca.

\section{MATERIAL E MÉTODOS}

Utilizou-se neste experimento cafés da cultivar Catuaí Vermelho IAC 144 (Coffea arabica L.) produzidos na Fazenda Experimental de MachadoMG, da Empresa de Pesquisa Agropecuária de Minas Gerais/EPAMIG.

Os frutos de café maduros, colhidos seletivamente, foram processados por via seca e via úmida. No processamento via seca, que resulta nos cafés naturais, os frutos foram lavados e selecionados manualmente, para garantir a uniformidade da amostra em relação ao estádio de maturação. No processamento do café via úmida, os frutos foram lavados e descascados mecanicamente, e divididos em duas parcelas. Uma parcela foi processada em desmucilador mecânico, originando os cafés desmucilados. A outra parcela foi submetida à desmucilagem por fermentação em água, por período de 20 horas, e lavados em água corrente até a retirada completa da mucilagem, originando os cafés despolpados. Depois desse período, os cafés em pergaminho foram lavados com água até a retirada completa da mucilagem.

Após o processamento, os cafés foram submetidos à secagem lenta e rápida até atingirem cerca de $11 \%$ de umidade (bu). Na secagem lenta, os cafés foram secados em camadas finas em telados suspensos à sombra, sendo revolvidos periodicamente. A secagem rápida foi realizada em

\section{REVENG}


secadores de camada fixa, com controle preciso do fluxo de ar e da temperatura a $35^{\circ} \mathrm{C}$. Os grãos foram secados em camada de $20 \mathrm{~cm}$ de espessura, com fluxo de ar controlado a $20 \mathrm{~m}^{3} \mathrm{~min}^{-1} \mathrm{~m}^{-2}$, correspondente a uma velocidade de $0,33 \mathrm{~m} \mathrm{~s}^{-1}$.

Após secagem, os grãos de cafés foram beneficiados e submetidos às seguintes avaliações: condutividade elétrica e lixiviação de potássio (PRETE, 1992), atividade enzimática da polifenoloxidase e acidez total titulável (CARVALHO et al., 1994). Realizou-se também, avaliação fisiológica, por meio do teste de germinação, computando-se a porcentagem de protusão radicular aos quinze dias, de germinação aos trinta dias e de folhas cotiledonares abertas aos 45 dias. O teste foi realizado em quatro subamostras de 50 sementes, distribuídas em papel de germinação umidecido, com quantidade de água equivalente a duas vezes e meia a massa do substrato seco, sob temperatura constante de 30 ${ }^{\circ} \mathrm{C}$, segundo as Regras para Análise de Sementes (BRASIL, 2009).

A análise sensorial foi realizada por profissionais credenciados pela Associação Brasileira de Cafés Especiais (BSCA). A metodologia utilizada na avaliação sensorial foi a mesma do $\mathrm{CoE}$ ("Cup of Excellence"), na qual cada atributo (bebida limpa, doçura, acidez, corpo, sabor, sabor remanescente, balanço ou equilíbrio e nota geral) recebe nota de 0 a 8 , de acordo com a intensidade, sendo por isso mais objetiva que a "prova de xícara" convencional. A somatória das notas corresponde à classificação final da bebida. Cada amostra recebe uma pontuação pré-estabelecida de 36 pontos, à qual são somadas as notas de cada atributo, sendo classificadas como cafés especiais aquelas que apresentam pontuação superior a 80 (BSCA, 2008).

$\mathrm{O}$ delineamento experimental foi inteiramente casualizado em esquema fatorial de $3 \times 2$, sendo três formas de processamento (café natural, desmucilado e despolpado) e dois métodos de secagem (lenta à sombra e rápida em secador mecânico), com quatro repetições. Os resultados obtidos das avaliações foram submetidos à análise de variância, utilizando-se o programa computacional Sisvar 4.0, sendo as médias comparadas pelo teste de Scott-Knott em nível de $5 \%$ de significância.

\section{RESULTADOS E DISCUSSÃO}

Os resultados da análise sensorial em função dos diferentes métodos de processamento e de secagem testados são apresentados nos Quadros 1 e 2, onde são analisadas a pontuação total da bebida, bem como as pontuações obtidas nos diversos atributos avaliados. Segundo Malta (2011), na avaliação de cafés especiais é importante a avaliação de todos os atributos observados, uma vez que já existe uma significativa parcela do mercado para cafés especiais, onde são descritas e valorizadas características sensoriais distintas, o que somente pode ser diagnosticada com uma análise sensorial mais elaborada.

No Quadro 1 são apresentadas as notas médias dos atributos sensoriais bebida limpa, doçura, acidez, corpo, gosto remanescente e nota geral em função dos métodos de processamento e de secagem utilizados. Observa-se que não houve efeito significativo da interação dos fatores formas de processamento e métodos de secagem, sobre as variáveis qualitativas. Em relação ao método de processamento adotado, não se observaram diferenças significativas para os atributos sensoriais bebida limpa, corpo e gosto remanescente. Entretanto, observam-se diferenças significativas nos atributos sensoriais doçura, acidez e nota geral, em função do método de processamento adotado. A menor nota média do atributo doçura foi verificada nos cafés desmucilados, sendo que os cafés naturais e despolpados apresentaram notas que não diferiram significativamente.

Em relação ao atributo acidez, observa-se que o café despolpado apresentou a maior nota média. É importante ressaltar que a acidez pode ser um atributo desejável ou não, dependendo do ácido predominante na bebida. Uma acidez agradável contribui para a vivacidade do café, aumentando a percepção da doçura e confere característica de fruta fresca. Em geral, cafés que apresentam baixa acidez não apresentam nota sensorial elevada (SCAA, 2008). Geralmente, os cafés despolpados apresentam atributos sensoriais que os distinguem dos cafés processados por via seca, como acidez mais acentuada. 
Quanto ao método de secagem, percebe-se que os cafés secados de forma mais lenta, apresentaram notas superiores em todos os atributos sensoriais, com exceção do corpo (Quadro 1), indicando que este tipo de secagem possibilitou a obtenção de cafés de melhor qualidade sensorial do que a secagem rápida. Oliveira (2010) também verificou diferenças na qualidade sensorial de cafés submetidos a diferentes métodos de secagem, sendo que os cafés secados com ar aquecido apresentaram menores valores de acidez, corpo e finalização, quando comparados com os cafés secados em terreiro, indicando pior qualidade sensorial dos cafés secados com ar aquecido.

Para os atributos sabor, balanço e nota total, houve interação significativa entre as formas de processamento e os métodos de secagem utilizados, conforme resultados apresentados no Quadro 2. Em relação ao tipo de processamento, observa-se que os cafés submetidos à secagem rápida não se diferenciaram nos atributos sabor e balanço. Entretanto, os cafés despolpados, juntamente com os naturais, apresentaram as maiores notas sensoriais no atributo sabor e maiores notas no atributo balanço quando secados de forma lenta. O sabor representa a principal característica do café. Esta avaliação reflete a combinação de todas as percepções observadas na gustação. A pontuação dada ao sabor relata a intensidade, qualidade e complexidade da combinação entre o gosto e aroma sentido quando o café é provado (SCAA, 2008).

Observa-se ainda que os cafés despolpados e submetidos à secagem lenta e rápida apresentaram maiores valores para a nota sensorial total, indicando maior tolerância destes cafés ao processo de secagem com ar aquecido, quando comparado com os cafés naturais. Este fato foi, também, verificado por outros autores (OLIVEIRA, 2010; TAVEIRA, 2009).

Quadro 1. Notas médias de atributos sensoriais dos cafés submetidos a diferentes formas de processamento e de secagem

\begin{tabular}{lcccccc}
\hline Processamento & BL $^{*}$ & Doçura & Acidez & Corpo & GR $^{* *}$ & Geral \\
\hline Natural & $6,00 \mathrm{~A}$ & $6,50 \mathrm{~A}$ & $5,92 \mathrm{~B}$ & $6,00 \mathrm{~A}$ & $5,83 \mathrm{~A}$ & $5,83 \mathrm{~B}$ \\
Desmucilado & $6,17 \mathrm{~A}$ & $5,92 \mathrm{~B}$ & $6,17 \mathrm{~B}$ & $6,17 \mathrm{~A}$ & $5,87 \mathrm{~A}$ & $6,17 \mathrm{~A}$ \\
Despolpado & $6,25 \mathrm{~A}$ & $6,50 \mathrm{~A}$ & $6,75 \mathrm{~A}$ & $6,00 \mathrm{~A}$ & $6,04 \mathrm{~A}$ & $6,25 \mathrm{~A}$ \\
\hline Secagem & $\mathrm{BL}$ & Doçura & Acidez & Corpo & GR & Geral \\
\hline Rápida & $6,00 \mathrm{~B}$ & 5,83 B & $6,00 \mathrm{~B}$ & $6,00 \mathrm{~A}$ & $5,72 \mathrm{~B}$ & $5,89 \mathrm{~B}$ \\
Lenta & $6,28 \mathrm{~A}$ & $6,78 \mathrm{~A}$ & $6,55 \mathrm{~A}$ & $6,11 \mathrm{~A}$ & $6,11 \mathrm{~A}$ & $6,28 \mathrm{~A}$ \\
\hline
\end{tabular}

Médias seguidas pelas mesmas letras maiúsculas na vertical não diferem estatisticamente entre si, pelo teste de ScottKnott a 5\% de probabilidade.

* Bebida Limpa; ** Gosto Remanescente

Quadro 2. Notas médias de atributos sensoriais dos cafés submetidos a diferentes formas de processamento e de secagem

\begin{tabular}{lcccccc}
\hline \multirow{2}{*}{ Processamento } & \multicolumn{2}{c}{ Sabor } & \multicolumn{2}{c}{ Balanço } & \multicolumn{2}{c}{ Nota Total } \\
\cline { 2 - 7 } & Rápida & Lenta & Rápida & Lenta & Rápida & Lenta \\
\hline Natural & $5,67 \mathrm{Ab}$ & $6,83 \mathrm{Aa}$ & $6,00 \mathrm{Aa}$ & $6,00 \mathrm{Ba}$ & $82,50 \mathrm{Bb}$ & $86,17 \mathrm{Ba}$ \\
Desmucilado & $6,00 \mathrm{Aa}$ & $6,33 \mathrm{Ba}$ & $6,00 \mathrm{Aa}$ & $6,00 \mathrm{Ba}$ & $83,25 \mathrm{Bb}$ & $86,00 \mathrm{Ba}$ \\
Despolpado & $6,25 \mathrm{Ab}$ & $7,00 \mathrm{Aa}$ & $6,00 \mathrm{Ab}$ & $6,67 \mathrm{Aa}$ & $84,50 \mathrm{Ab}$ & $89,00 \mathrm{Aa}$ \\
\hline
\end{tabular}

Médias seguidas pelas mesmas letras maiúsculas nas colunas e minúsculas nas linhas, não diferem estatisticamente entre si, pelo teste de Scott-Knott a 5\% de probabilidade. 
Em relação ao tipo de secagem, nota-se que os cafés despolpados, secados de forma lenta, apresentaram as maiores notas para os atributos sabor e balanço. Já em relação à nota sensorial total, nota-se que a secagem lenta apresentou melhores resultados sensoriais que a secagem rápida em todas as formas de processamento avaliadas. As menores notas sensoriais observadas nos cafés secados com ar aquecido (secagem rápida) indicam possíveis danos aos componentes celulares dos grãos de café submetidos a esse tipo de secagem (ILLY, 2002). De acordo com Borém et al. (2008) e Saath et al. (2010), os sistemas de membranas celulares dos grãos de café são particularmente danificados quando os cafés apresentam teores de água entre $30 \%$ e $20 \%$ (bu), e são submetidos a temperaturas de secagem próximas de $60^{\circ} \mathrm{C}$, tanto para os cafés despolpados como para os cafés naturais. Marques et al. (2008) verificaram que a temperatura de secagem de $40{ }^{\circ} \mathrm{C}$ favorece a obtenção de cafés de melhor qualidade do que as demais temperaturas avaliadas $\left(50{ }^{\circ} \mathrm{C}\right.$ e $\left.60{ }^{\circ} \mathrm{C}\right)$. Entretanto, a secagem com ar aquecido, no presente trabalho, ocorreu numa temperatura controlada de $35^{\circ} \mathrm{C}$, tendo, mesmo assim, propiciado perda de qualidade dos cafés naturais, quando comparados com aqueles submetidos à secagem lenta.

Corroborando com os resultados aqui apresentados, Oliveira (2010), também verificou maiores valores para a nota sensorial total nos cafés secados em terreiro quando comparados com os secados com ar aquecido. Entretanto, segundo o mesmo autor, para o café despolpado, o aumento da temperatura de secagem não teve influência na nota total quando comparados aos cafés naturais, fato aqui observado, o que pode estar relacionado com a menor temperatura de secagem do ar aquecido empregado neste trabalho. Embora utilizando temperaturas de secagem superiores ao do presente trabalho, Taveira (2009), observou que os cafés despolpados apresentaram maior tolerância a altas temperaturas, quando comparados com os cafés naturais, o que segundo o autor, poderia estar relacionado ao menor tempo de exposição à secagem e, consequentemente, à manutenção da qualidade.

Dessa forma, de acordo com os resultados obtidos, percebe-se que mesmo baixas temperaturas de secagem, como a utilizada neste experimento, podem contribuir para a perda de qualidade dos cafés, independentemente do tipo de processamento utilizado, o que pode ser atribuído as maiores taxas de secagem, com efeitos mais pronunciados nos cafés naturais. Esses resultados estão de acordo com os obtidos por Isquierdo (2011), o qual afirma que a taxa de secagem interfere na qualidade do café natural, concluindo que a elevação da taxa de secagem, sob temperaturas de $35{ }^{\circ} \mathrm{C}$ e $40{ }^{\circ} \mathrm{C}$, tem efeito negativo na qualidade do café natural. Ainda segundo este autor, o café natural, submetido à temperatura de secagem de $35{ }^{\circ} \mathrm{C}$ e $40^{\circ} \mathrm{C}$, apresentou notas de fragrância, sabor, acidez e corpo e nota total significativamente maiores na análise sensorial realizada logo após a secagem, quando comparados com cafés submetidos à temperatura de secagem de $45^{\circ} \mathrm{C}$, reforçando o efeito negativo da secagem a temperaturas mais altas. Afonso Júnior et al. (2004b), também verificaram que frutos e grãos de café secos em terreiro também apresentaram melhores resultados sensoriais ao longo do armazenamento quando comparados com aqueles secos mecanicamente.

Os resultados das avaliações fisiológicas em função das diferentes formas de processamento e de secagem são apresentados nos Quadros 3 e 4. Verifica-se que houve efeito significativo da interação entre processamento e secagem sobre os percentuais de protusão radicular e de germinação (Quadro 3). Assim como observado na análise sensorial, os cafés naturais apresentaram piores resultados fisiológicos, evidenciados pelos menores percentuais de protusão radicular e de germinação, quando foram submetidos à secagem rápida, em comparação às demais formas de processamento. Na secagem lenta não foram verificadas diferenças significativas entre as formas de processamento avaliadas de acordo com as análises fisiológicas. Entretanto, Oliveira (2010) constatou que cafés naturais secados em terreiro apresentaram indicativos de atividade fisiológica. Nos tratamentos com ar aquecido, os cafés naturais apresentaram valores nulos, indicando a morte dos embriões dos grãos de café durante o processo de secagem, o que, segundo o autor, reforça as observações de que estes cafés são mais sensíveis à secagem, principalmente com temperaturas 
mais elevadas (TAVEIRA, 2009). Ressalta-se, entretanto, que os cafés naturais do presente trabalho foram secados com ar aquecido a $35^{\circ} \mathrm{C}$, o que, provavelmente, provocou menores danos aos grãos de café. Já Oliveira (2010), trabalhando com temperaturas de secagem alternadas de $50 / 40{ }^{\circ} \mathrm{C}$, $40 / 60{ }^{\circ} \mathrm{C}$ e $60 / 40{ }^{\circ} \mathrm{C}$, observou danos mais intensos na qualidade fisiológica dos grãos de café do que os observados neste trabalho.

Observa-se ainda, pelos resultados do Quadro 3 , que os cafés processados por via úmida não tiveram efeito negativo da secagem com ar aquecido, tendo apresentado altos percentuais de germinação. Oliveira (2010) também verificou atividade fisiológica (protusão radicular, germinação e folhas cotiledonares) nos cafés despolpados, sendo que nos naturais, secados com ar aquecido, apresentaram valores nulos nestas variáveis. Segundo Taveira (2009), aparentemente os cafés despolpados apresentam maior tolerância à temperaturas de secagem mais altas, quando comparados aos cafés naturais. Afonso Júnior (2001), estudando aspectos físicos, fisiológicos e de qualidade sensorial de grãos de café em função da secagem e do armazenamento, afirma que a qualidade dos cafés descascados e despolpados é menos afetada em relação à dos cafés naturais. Segundo esse autor, a variação da temperatura do ar de secagem é a responsável em grande parte por essa perda, enquanto que variações na umidade relativa do ar de secagem tem menor influência sobre a qualidade sensorial.

Percebe-se assim, relação direta entre as análises fisiológicas e a análise sensorial, em que se verifica que cafés despolpados, além de apresentarem maiores valores nas análises fisiológicas, também apresentam maiores notas sensoriais quando submetidos ao despolpamento, fato este corroborado por outros autores (OLIVEIRA, 2010; TAVEIRA, 2009).

Quadro 3. Resultados das avaliações fisiológicas de cafés submetidos a diferentes formas de processamento e métodos de secagem

\begin{tabular}{lcccc}
\hline \multirow{2}{*}{ Processamento } & \multicolumn{4}{c}{ Secagem } \\
\cline { 2 - 5 } & \multicolumn{2}{c}{ Protusão radicular (\%) } & \multicolumn{2}{c}{ Germinação (\%) } \\
\cline { 2 - 5 } & Rápida & Lenta & Rápida & Lenta \\
\hline Natural & $45,50 \mathrm{Bb}$ & $92,50 \mathrm{Aa}$ & $26,00 \mathrm{Bb}$ & $84,50 \mathrm{Aa}$ \\
Desmucilado & $92,00 \mathrm{Aa}$ & $92,50 \mathrm{Aa}$ & $83,00 \mathrm{Ab}$ & $92,50 \mathrm{Aa}$ \\
Despolpado & $95,00 \mathrm{Aa}$ & $94,00 \mathrm{Aa}$ & $82,00 \mathrm{Aa}$ & $88,50 \mathrm{Aa}$ \\
\hline
\end{tabular}

Médias seguidas pelas mesmas letras maiúsculas nas colunas e minúsculas nas linhas, não diferem estatisticamente entre si, pelo teste de Scott-Knott a 5\% de probabilidade.

Quadro 4. Resultados das avaliações fisiológicas de cafés submetidos a diferentes formas de processamento e métodos de secagem

\begin{tabular}{lc}
\hline Processamento & Folhas cotiledonares $(\%)$ \\
\hline Natural & $15,75 \mathrm{C}$ \\
Desmucilado & $37,75 \mathrm{~A}$ \\
Despolpado & $24,75 \mathrm{~B}$ \\
\hline Secagem & Folhas cotiledonares $(\%)$ \\
\hline Rápida & $16,67 \mathrm{~B}$ \\
Lenta & $35,00 \mathrm{~A}$ \\
\hline
\end{tabular}

Médias seguidas pelas mesmas letras maiúsculas na coluna não diferem estatisticamente entre si, pelo teste de ScottKnott a 5\% de probabilidade. 
Quando os grãos de café foram submetidos à secagem lenta, não foram verificadas diferenças significativas entre os tipos de processamentos adotados para protrusão radicular e germinação. Entretanto, Oliveira (2010) verificou efeitos significativos de diferentes tipos de secagem ao comparar os cafés processados por via úmida e via seca secados em terreiro. Segundo o autor, os cafés naturais, processados por via seca e secados em terreiro ao sol, apresentaram menores valores em todas as avaliações fisiológicas, o que poderia indicar que ocorreram mais danos fisiológicos nos grãos de café submetidos a esse tipo de processamento. Cabe ressaltar que os cafés naturais em questão foram submetidos a secagem em terreiros ao sol, diferentemente do presente trabalho, que foram secados em telados suspensos a sombra.

No Quadro 4 se observa que os cafés submetidos a secagem lenta apresentaram melhor qualidade fisiológica, avaliada pelo percentual de plântulas com folhas cotiledonares abertas, em relação a secagem rápida, o que sugere que essa forma de secagem provocou menores danos fisiológicos aos grãos de café. Verifica-se ainda que os cafés naturais apresentaram os menores percentuais de folhas cotiledonares abertas que as demais formas de processamento. Oliveira (2010) também verificou que os cafés naturais apresentaram os menores valores em todas as avaliações fisiológicas realizadas, o que, segundo o autor, sugere danos fisiológicos mais intensos nos grãos de café submetidos a esse tipo de processamento.

Menor percentual de plântulas com folhas cotiledonares abertas foi observado nos cafés submetidos a secagem rápida, independente do tipo de processamento adotado, o que denota efeito negativo desse tipo de secagem sobre a qualidade fisiológica, corroborando com os resultados da análise sensorial anteriormente discutida. Segundo Oliveira (2010), o uso de ar aquecido permite a secagem mais rápida, entretanto, pode provocar alterações indesejáveis nas membranas celulares dos grãos de café, resultando na redução de vigor das sementes, potencial de emergência e desenvolvimento de plântulas normais e até mesmo na perda total da viabilidade, definida como a capacidade de produzir plântulas normais.

Analisando-se os resultados apresentados nos Quadros 5 e 6, verifica-se menores valores de condutividade elétrica, lixiviação de potássio, acidez total titulável e maior atividade enzimática da polifenoloxidase nos cafés submetidos à secagem lenta à sombra, independente da forma de processamento utilizado. Esses resultados indicam menos danos aos sistemas de membranas celulares durante a secagem mais lenta, processada com menores taxas de remoção de água. Assim, a secagem lenta apresenta potencial para produção de cafés de melhor qualidade, o que foi confirmado pelos resultados da análise sensorial e fisiológica, discutidas anteriormente.

Em relação ao tipo de processamento, observase pelos resultados apresentados no Quadro 5, que os cafés naturais apresentaram maiores valores de condutividade elétrica e de lixiviação de potássio, quando submetidos à secagem rápida, ou seja, em secadores mecânicos, demonstrando maior probabilidade de perda de qualidade, provavelmente devido à maior sensibilidade desses cafés ao processo de secagem com ar aquecido que as demais formas de processamento. Esses resultados estão de acordo com trabalhos recentes, os quais confirmam que os cafés despolpados são mais tolerantes à secagem que os cafés naturais, independentemente do método de secagem a que são submetidos. Segundo Taveira (2009), o café despolpado é mais tolerante à secagem do que o café natural, independente do método de secagem, apresentando melhor qualidade fisiológica. Resultados semelhantes também foram verificados por Oliveira (2010), que observou maiores valores de condutividade elétrica e de lixiviação de potássio nos cafés naturais, quando comparados com os cafés despolpados, o que, segundo o autor, é resultado da manutenção das estruturas celulares e da qualidade do café despolpado. Segundo Prete (1992), a maior tolerância de cafés despolpados à secagem, em relação aos cafés naturais, está relacionada ao menor tempo de exposição a altas temperaturas, devido à remoção do exocarpo e da mucilagem. 
Quadro 5. Valores médios de condutividade elétrica $\left(\mu \mathrm{S} \mathrm{cm}^{-1} \mathrm{~g}^{-1}\right.$ de amostra) e de lixiviação de potássio $\left(\mathrm{mg} \cdot \mathrm{kg}^{-1}\right)$ de cafés submetidos a diferentes formas de processamento e métodos de secagem

\begin{tabular}{lcccc}
\hline \multirow{2}{*}{ Processamento } & \multicolumn{3}{c}{ Secagem } \\
\cline { 2 - 5 } & \multicolumn{2}{c}{ Condutividade } & \multicolumn{2}{c}{ Lixiviação de Potássio } \\
\cline { 2 - 5 } & Rápida & Lenta & Rápida & Lenta \\
\hline Natural & $157,06 \mathrm{Aa}$ & $95,73 \mathrm{Ab}$ & $37,79 \mathrm{Aa}$ & $18,77 \mathrm{Ab}$ \\
Desmucilado & $126,02 \mathrm{Ba}$ & $95,96 \mathrm{Ab}$ & $27,82 \mathrm{Ba}$ & $19,77 \mathrm{Ab}$ \\
Despolpado & $124,20 \mathrm{Ba}$ & $77,69 \mathrm{Bb}$ & $25,34 \mathrm{Ba}$ & $16,20 \mathrm{Ab}$ \\
\hline
\end{tabular}

Médias seguidas pelas mesmas letras maiúsculas nas colunas e minúsculas nas linhas, não diferem estatisticamente entre si, pelo teste de Scott-Knott a 5\% de probabilidade.

Quadro 6. Valores médios de atividade enzimática da polifenoloxidase/PPO ( $\mathrm{u} \mathrm{min}^{-1} \mathrm{~g}^{-1}$ de amostra) e


formas de processamento e métodos de secagem

\begin{tabular}{|c|c|c|c|c|}
\hline \multirow{3}{*}{ Processamento } & \multicolumn{4}{|c|}{ Secagem } \\
\hline & \multicolumn{2}{|c|}{ PPO } & \multicolumn{2}{|c|}{ Acidez Total } \\
\hline & Rápida & Lenta & Rápida & Lenta \\
\hline Natural & $36,66 \mathrm{Ab}$ & $41,32 \mathrm{Aa}$ & $150,00 \mathrm{Aa}$ & $146,66 \mathrm{Aa}$ \\
\hline Desmucilado & $36,42 \mathrm{Ab}$ & $40,00 \mathrm{Aa}$ & $148,33 \mathrm{Aa}$ & $133,33 \mathrm{Bb}$ \\
\hline Despolpado & $36,50 \mathrm{Ab}$ & $41,07 \mathrm{Aa}$ & $156,66 \mathrm{Aa}$ & $133,33 \mathrm{Bb}$ \\
\hline
\end{tabular}

Médias seguidas pelas mesmas letras maiúsculas nas colunas e minúsculas nas linhas, não diferem estatisticamente entre si, pelo teste de Scott-Knott a 5\% de probabilidade.

Em relação ao tipo de secagem, verifica-se que os cafés secados com ar aquecido apresentaram maiores valores de condutividade elétrica e lixiviação de potássio quando comparados com os cafés secados de forma lenta, independentemente da forma de processamento. Resultados semelhantes foram observados por Coradi et al. (2007) e Oliveira (2010), os quais verificaram que o aumento da temperatura do ar de secagem também resultou em maiores valores nestas análises, tanto nos cafés processados por via úmida quanto por via seca, sugerindo que o aumento da temperatura de secagem pode ocasionar danos ao sistema de membranas celulares. Coradi e Borém (2009) verificaram maiores valores de condutividade elétrica e lixiviação de potássio apenas quando foram empregadas temperaturas de secagem de $60^{\circ} \mathrm{C}$, sendo que os cafés secados ao sol e com temperaturas de $40{ }^{\circ} \mathrm{C}$ não apresentaram diferenças significativas.

\section{CONCLUSÕES}

- Há interação entre métodos de processamento e de secagem sobre a qualidade sensorial do café, sendo mais evidentes os efeitos da secagem;

- Os cafés obtidos por via úmida apresentam maior tolerância à secagem do que os processados por via seca;

- Melhor qualidade sensorial é obtida nos cafés submetidos à secagem lenta, independentemente da forma de processamento utilizada;

- Cafés de melhor qualidade sensorial apresentam melhor qualidade fisiológica, avaliada pela condutividade elétrica, lixiviação de potássio e teste de germinação.

\section{REVENG}




\section{REFERÊNCIAS BIBLIOGRAFICAS}

AFONSO JÚNIOR, P.C. Aspectos físicos, fisiológicos e de qualidade do café em função da secagem e do armazenamento. 2001. 384f. Tese (Doutorado em Engenharia Agrícola) Universidade Federal de Viçosa, Viçosa, 2001.

AFONSO JÚNIOR, P.C.; CORRÊA, P.C.; GONELI, A.L.D.; VILARINHO, M.C.; FRANÇA, A.S. Dinâmica da contração volumétrica do fruto de café durante o processo de secagem. Revista Brasileira de Armazenamento, Viçosa, n.8, p.29-35, 2004a.

AFONSO JÚNIOR, P.C.; CORRÊA, P.C.; GONELI, A.L.D.; SILVA, F.S. Contribuição das etapas do pré-processamento para a qualidade do café. Revista Brasileira de Armazenamento, Viçosa, n.8, p.46-53, $2004 b$.

BORÉM, F.M.; MARQUES, E.R.; ALVES, E. Ultrastructural analysis damage in parchment Arabica coffee endosperm cells. Biosystems Engineering, v.99, n.1, p.62-66, 2008. Disponível em: $\quad<$ http://www.sciencedirect.com/science/ article/pii/S153751100700267X>. Acesso em: 11 Dez. 2012. doi: 10.1016/j.bbr.2011.03.031

BRASIL. Ministério da Agricultura e Reforma Agrária. Secretaria Nacional de Defesa Agropecuária. Regras para análises de sementes. Brasília, 2009. 399p.

BRAZIL SPECIALITY COFFEE ASSOCIATION. Cafés especiais. Varginha, 2005. Disponível em: $<$ http://bsca.com.br>. Acesso em: 10 jan. 2008.

BYTOF, G.; SELMAR, D.; SCHIEBERLE, P. New aspects of coffee processing: How do the different post harvest treatments influence the formation of potential flavour precursors? Journal of Applied Botany, v.74, n.3/4, p.131-136, 2000.

BYTOF, G; KNOPP, S.E.; SCHIEBERLE, P.; TEUTSCH, I.; SELMAR, D. Influence of processing on the generation of $\gamma$-aminobutiric acid in green coffee beans. European Food Research and Technology, v.220, p.245-250, 2005. Disponível em: <http://link. springer.com/article/10.1007\%2Fs00217-004-1033z?LI=true >. Acesso em: 12 Dez. 2012. doi: 10.1007/ s00217-004-1033-z.
CARVALHO, V.D.; CHAGAS, S.J.R.; CHALFOUN, S.M.; BOTREL, N.; JUSTE JUNIOR, E.S.G. Relação entre a composição físico-química e química do grão beneficiado e a qualidade da bebida do café. Pesquisa Agropecuária Brasileira, v.29, n.3, p.449-454, 1994.

CORADI, P.C.; BORÉM, F.M. Alterações dos parâmetros físico-químicos na qualidade da bebida do café natural e despolpado em função de diferentes tipos de secagem e condição de armazenamento. Revista Brasileira de Armazenamento, n.11, p.54-63, 2009.

CORADI, P.C.; BORÉM, F.M.; SAAHT, R.; MARQUES, E.R. Effect of drying and storage conditions on the quality of natural and washed coffee. Coffee Science, v.2, n.1, p.38-47, 2007. Disponível em: <https://www.coffeescience.ufla. br/index.php/Coffeescience/article/view/37/33>. Acesso em: 12 Dez. 2012.

CORREAA, P.C.; AFONSO JÚNIOR, P.C.; QUEIROZ, D.M. de; SAMPAIO, C.P.; CARDOSO, J.B. Variação nas dimensões características e da forma dos frutos de café durante o processo de secagem. Revista Brasileira de Engenharia Agrícola e Ambiental, v.6; n.3, p.466-470, 2002. Disponível em: <http://www.scielo.br/ scielo.php?script=sci_arttext\&pid=S141543662 $002000300014 \& \operatorname{lng}=p t \&$ tlng $=p t>$. Acesso em: 12 Dez. 2012. http://dx.doi.org/10.1590/S141543662002000300014

ILLY, E. A saborosa complexidade do café: A ciência que está por trás de um dos prazeres simples da vida. Scientific American Brasil. Disponível em: <http://www2.uol.com.br/sciam/ reportagens/a_saborosa_complexidade_do_cafe. html>. Acesso em: 12 Dez. 2012.

ISQUIERDO, E.P. Cinética de secagem de café natural e suas relações com a qualidade para diferentes temperaturas e umidades relativas do ar. 2011. 157p. Tese (Doutorado em Engenharia Agrícola) - Universidade Federal de Lavras, Lavras, 2011. 
KNOPP, S.E.; BYTOF, G.; SELMAR, D. Influence of processing on the cont of sugars in green arabica coffee beans. European Food Research and Technology, v.223, n.2, p.195201, 2006. Disponível em: <http://link.springer. com/article/10.1007\%2Fs00217-005-01721?LI=true\#page-1>. Acesso em: 12 Dez. 2012. doi: 10.1007/s00217-005-0172-1

MALTA, M.R. Critérios utilizados na avaliação da qualidade do café. Informe Agropecuário, v.32, n.261, p.114-126, 2011.

MALTA, M.R. CHAGAS, S.J.R.; CHALFOUN, S.M. Colheita e pós-colheita do café: recomendações e coeficientes técnicos. Informe Agropecuário, v.29, n.247, p.83-94, 2008.

MALTA, M.R.; PEREIRA, R.G.F.A.; CHAGAS, S.J. de R. Condutividade elétrica e lixiviação de potássio no exsudato de grãos de café: alguns fatores que podem influenciar essas avaliações. Ciência e Agrotecnologia, v.29, n.5, p.10151020, 2005. Disponível em: <http://www.scielo. br/scielo.php?script $=$ sci_arttext\&pid $=$ S1413 $70542005000500015 \& \operatorname{lng}=$ en\&nrm $=$ iso $>$. Acesso em: 12 Dez. 2012. http://dx.doi.org/10.1590/ S1413-70542005000500015

MARQUES, E.R.; BORÉM, F.M.; PEREIRA, R.G.F.A.; BIAGGIONI, M.A.M. Eficácia do teste de acidez graxa na avaliação da qualidade do café arábica (Coffea arabica L.) submetido a diferentes períodos e temperaturas de secagem. Ciência e Agrotecnologia, v.32, n.5, p.1557-1562, 2008. Disponível em: $<$ http://www.scielo.br/scielo.php?script $=$ sci arttext\&pid=S1413-70542008000500030\&lng=en\& nrm=iso $>$. Acesso em: 12 Dez. 2012. http://dx.doi. org/10.1590/S1413-70542008000500030

OLIVEIRA, P.D. de. Aspectos ultraestruturais e fisiológicos associados à qualidade da bebida de café arábica submetido a diferentes métodos de processamento e secagem. 2010. 108p. Dissertação (Mestrado em Engenharia Agrícola) Universidade Federal de Lavras, Lavras, 2010.

PRETE, C.E.C. Condutividade elétrica do exsudato de grãos de café (Coffea arabica L.) e sua relação com a qualidade da bebida. 1992. 125f. Tese (Doutorado em Agronomia) Escola Superior de Agricultura Luiz de Queiroz, Piracicaba, 1992.

RIBEIRO, D.M.; BORÉM, F.M.; ANDRADE, E.T. de.; ROSA, S.D.V.F. da. Taxa de redução de água do café cereja descascado em função da temperatura da massa, fluxo de ar e período de présecagem. Revista Brasileira de Armazenamento, v.28, n.7, p.94-107, 2003.

SAATH, R.; BORÉM, F.M.;ALVES, E.; TAVEIRA, J.H.S; MÉDICE, R., CORADI, P.C. Microscopia eletrônica de varredura do endosperma de café (Coffea arabica L.) durante o processo de secagem. Revista Ciência e Agrotecnologia, n.34, p.196203, 2010. Disponível em: <http://www.scielo. br/scielo.php?script $=$ sci_arttext\&pid $=\mathrm{S} 1413$ $70542010000100025 \& \operatorname{lng}=$ pt\&nrm $=$ iso $>$ Acesso em: 12 Dez. 2012. http://dx.doi.org/10.1590/ S1413-70542010000100025

SPECIALTY COFFEE ASSOCIATION OF AMERICA. Protocolo para análise sensorial de café: metodologia SCAA. [S.1.], 2008. Disponível em: $\quad<$ http://coffeetraveler.net/wp-content/ files/901-SCAA_CuppingProtocols_TSC_DocV RevDec08_Portuguese.pdf $>$. Acesso em: 12 Dez. 2012.

TAVEIRA, J.H.S. Aspectos fisiológicos e bioquímicos associados à qualidade da bebida de café submetido a diferentes métodos de processamento e secagem. 2009. 67f. Dissertação (Mestrado em Engenharia Agrícola) - Universidade Federal de Lavras, Lavras, 2009. 